\title{
Teaching of Lexical Chunks in the Application of Listening Teaching Chinese as a Foreign Language
}

\author{
XiaoQing Zou, ShuPeng Bai \\ North China Institute of Science and Technology, Yan Jiao, China
}

\begin{abstract}
The listening comprehension is a complex process of interaction between language and thinking, listening ability is a core skills in Chinese communication skills. Teaching advocates use of lexical chunks in the teaching of lexical chunks, on improving Chinese as a foreign language listening ability has certain advantages. This paper argues that the use of lexical chunks in the teaching Chinese as a foreign language teaching, help students to establish consciousness of lexical chunks, students can speed up the processing listening material information, to improve the students' listening level.
\end{abstract}

KEYWORDS: Teaching of lexical chunks; Chinese as a foreign language; Listening; strategy

Listening is a major means of access to information, no listening, and no speaking, also can't communicate with language . In teaching Chinese as a foreign language, listening course has always been considered a difficult lesson, teaching efficiency is low, the enthusiasm of students is not high, is fear for the hearing. Investigate its reason, in the listening exercises, students can't concentrate on the full understanding of the material content, but stay in trying to catch every pronunciation, to understand a Chinese character, in the language flow processing semantic ability is poor. Theory of lexical chunks, from a new point of this paper expounds the theory and practice of language teaching, fundamentally put forward on how to improve students' listening comprehension ability of Chinese response, offers a new way and perspectives for listening teaching Chinese as a foreign language.

\section{THE TEACHING OF LEXICAL CHUNKS}

\subsection{The definition of lexical chunks}

With the rapid development of corpus linguistics, people gradually found that there are many ingredients in our output of language is not temporary assembly made up of those elements, but directly from lexical chunks. Lexical chunks are gradually into the study of second language acquisition and become a hot spot of linguistic increasingly. Put forward the concept of "set" is the American psychologist, Miller \& Sdfridge, he thinks that represents the memory block of information processing, ----the individual information into a larger unit. Becker, from the perspective of linguistics defines "Lexical chunks" : in language use, as a human memory and storage, output, and use a fixed or semi-fixed modeled plate structure, it is the smallest unit of human communication. Nattinger \& Decarrico language chunks theory, points out that person's memory in the presence of large amounts of prefabricated language unit, also is the information of lexical chunks, consists of a few words, but words contain more information than a single. The normal use of a language, is to choose the prefabricated lexical chunks, and put them together in the process of lexical chunks.

According to the characteristics of the Chinese, chunks refers to those in the language communication as a whole unit to sense, understand and use the language of the project, including the words phrases, idioms, all kinds of strength matching and the habit of fixed and semi-fixed expressions. Exist in Chinese language block structure, most natural discourse is accomplished by language chunks. Can be used as the ideal unit for storage and output of lexical chunks, is advantageous to the accuracy, and appropriateness of language expression.

\subsection{The basic point of teaching of lexical chunks}

In teaching Chinese as a foreign language, grammar teaching occupy the central position for a long time since. In traditional grammar centered teaching, the rules of grammar is architecture, vocabulary is the 
filling of the same flesh and blood of the architecture, architecture, words can be arbitrary replacement, thus forming different sentences. But in the course of real practical teaching and students' words inputting, we found some sentences from the grammatical perspective is not wrong, but Chinese people usually don't say so, it sounds also feel uncomfortable. In actual communication, besides considering the accuracy of the discourse, to pay attention to the appropriateness of discourse and tunnels. Language teaching thought, language consists of different types of combination of lexical chunks, different lexical chunks compose different sentence, different sentence combinate paper, therefore, vocabulary table significance, both at the same time table structure. The lexical chunks approach can make students effectively use vocabulary common collocation, improve the efficiency of vocabulary memory, strengthen the feeling of Chinese and can speak sentences fluently and quickly. To sum up, language chunks teaching the core idea is "language is the vocabulary of grammaticalization, rather than the grammar of the lexicalization". Language teaching accords with the basic cognitive law of students, reducing the program and the difficulty of information processing, is feasible in the teaching.

\subsection{The type of Chinese lexical chunks}

At present, some scholars and education experts after a huge mass of data research and practice prove that there is this kind of structure of lexical chunks in Chinese phenomenon, mainly can be divided into several categories:

\subsubsection{The idioms.}

The idioms generally includes Chinese idioms, proverbs, xiehouyu, proverbs, sayings and aphorisms and so on. Idioms internal confused, but actually is not a mass of chaos, there is a hierarchy, some belong to the lexical level, some belong to the sentential level. its structure is stable, has a double meaning, conforms to the basic characteristics of fixity of lexical chunks. Such as " self-contradiction" "wait for windfalls" .

\subsubsection{The collocation of lexical chunks.}

Collocation of lexical chunks of the biggest characteristic is that it "co-occurrence", which is in the presence of a word to express a certain meaning and collocation of another word will appear at the same time, the finish is tie-in, expression meaning. Such as common associated words "if....." "not only......but also......" etc., "under......" "at+place" and so on, also belong to this category. Collocation of lexical chunks include those in the use process often appear words at the same time, such as see "opportunity" we will think of "Seize"; See "energetic" will think of "energy" and so on. This type of lexical chunks in speaking and listening teaching Chinese as a foreign language frequency of use can help learners to sum up, the important content of discourse understanding sentence meaning.

\subsection{3 frame phrase language chunks.}

This piece at first glance is a form of phrase, but in fact have a fixed structure framework, has formed a kind of solidification in the form of stored in the brain, the whole extraction is very convenient. Frame phrases including word frame phrase language chunks of lexical chunks, such as:"left......right......" "no......no......" And so on; Also includes sentence frame phrase language chunks, the frequently used sentence patterns in the spoken language, such as: "You See Yourself....." this kind of language is a kind of relatively fixed framework, once in the brain to form memories can form a chain effect, mass memory effects.

\subsection{4 formulas.}

Formulas are those that often appear, form relatively fixed, with a specific meaning or statements of pragmatic functions. In Chinese, there are some formulas, such as "I wish you a pleasant journey!" "happy birthday!" ; Session sets that is in a particular session answer structure, a trigger another line, often come in pairs, such as "- hello!- hello!" , "-sorry! -it doesn't matter! ".Another in oral expression, "not so good", "ok, ok!" said often fixed meaning and tone, such as "ok,ok!" often expression exhortation.

\section{THE TEACHING OF LEXICAL CHUNKS IN THE INCREASE OF THE ADVANTAGE OF CHINESE LISTENING COMPREHENSION ABILITY}

Use of lexical chunks in listening comprehension teaching, first of all, can effectively improve the efficiency of students' memory. In listening comprehension, divide a sentence according to the language chunks, reduced the amount of time short code, the number of one-time remember vocabulary will increase. Chinese word's often have many meanings and usages, memory alone has the certain difficulty, the effect is not good. Which is the significance of lexical chunks in the context of the specific, memory than from the context of lexical chunks of memory words alone difficulty smaller, better, to maintain a longer and not easily forgotten.

Second, lexical chunks is beneficial to the forecast information. Lexical chunks as a fixed or semi-fixed structure, often with situational, lexical chunks in the natural language plays a discourse, such as 
organization structure, the connection information and the important role of indicated below. Such as the frame part of lexical chunks can suggest another part of the content of the associated with it, for example: hear "because....." naturally know is the reason behind; Therefore, the more accumulation of lexical chunks, the listener can more effective use of lexical chunks to guess the next information, win process information for the further and reaction time.

Finally, the teaching of lexical chunks is helpful to improve the efficiency of understanding of the listening material. Lexical chunks are forms of language users are familiar with, so the listener is not strange to hear information, so as to shorten the normal language communication brain compress the time needed for processing language information, greatly reduced due to the real-time analysis and processing of information that pressure. Listening material containing the fleeting voice information, use of lexical chunks can quickly extract relevant information, avoid by a a word recognition, on the whole cognitive material, improve the efficiency of understanding of the listening material.

\section{THE USE OF LEXICAL CHUNKS IN LISTENING PRACTICE OF CHINESE TEACHING STRATEGY}

\subsection{Establish awareness of lexical chunks, and division lexical chunks in textbook}

Teachers should accept the theory of lexical chunks, and establish awareness of lexical chunks in the process of teaching, to guide students to change the past simple and superficial understanding of vocabulary, understand language is mainly composed of lexical chunks. In Chinese spoken language and written language in the presence of large amounts of lexical chunks, the collocation of use, high frequency, frame structure can be memory and extract as a whole, is the ideal vocabulary teaching of lexical chunks unit and oral communication.

On the writing of textbooks can also through the concept of lexical chunks, change the traditional teaching way of writing for the center with vocabulary and grammar. Structured fixed or semifixed phrases is prefabricated, can facilitate students' memory and control with words in the vocabulary. Such as: "put the... as a ", In practice and in the writing of the annotation, also want to list the word or structure of high frequency, to improve students' sensitivity to the lexical chunks. Such as: "improve", as the new words list in the vocabulary, can be listed in the training program, "conditions", "environment", "life", "relationship" as its common language chunks of memory, to listen to sound rapid extraction, and to enhance the students' Chinese language sense.

\subsection{Provide language chunks, strengthen the teaching of lexical chunks and memory}

In the process of language communication, there is always a certain theme, and use of lexical chunks and related formulas. So in listening teaching, the teacher wants to summarize a topic of lexical chunks in the teaching, combining the content of the new word table, promote students vocabulary memory into pieces of memory, improve the efficiency of memory. Such as when order a hotel, the commonly used language chunks are: Excuse me/you need hotel? / book/please wait/equipment/please fill out this form to register/etc. These phrases is typically as a whole is relatively easy to understand and grasp, use rise very convenient also.

To strengthen the teaching of lexical chunks to learn to memorize phrases. Recitation in the language acquisition, especially in foreign language learning is an essential link, is actually a kind of feasible way to actively, especially in primary level stage. Memorizing some ready-made language materials, is very beneficial to the improvement of language understanding and expression ability, which according to the division outline of idea function of language, such as requests, apologies, introduction, question, advice and wishes, advice, commitment, and complain the function such as project and said a few, multiples, such as the idea of the project, has a relatively fixed expressions, down to hear automatically extract, speed up the information decoding.

\subsection{The use of lexical chunks to forecast, combination, improve listening micro skills}

When students reserve a certain amount of lexical chunks, teacher should encourage students to use language chunks to bold guess in the process of listening. For example, when heard "first", to predict "second", "the third" or "the last", so as to know the topic includes three aspects; When they hear "According to a survey" language chunks, should focus on the language chunks back content, expressed by the positive transfer of lexical chunks, related to the topic so as to improve the ability of listening micro skills of imagine speculation and retrieve listening ability.

The are many words that its voice is the same or similar in Chinese, when students listen to the sound confusing, affect the understanding of semantics. Such as "Chinese" and "Korean", "private" and "poet", the pronunciation in Chinese is very similar, is not easy to distinguish when the students are listening to. In the process of listening, let the student through has stored knowledge to hear information of lexical chunks of language combination, quickly identify the correct meaning. Like to hear my "I want to learn Korean", the brain 
quickly put the "learn" and "Korean" into a lexical chunk, to hear the" Going to Korea next year, " the brain according to the storage of language knowledge, automatic link this "Korea" and "Korean", to eliminate the "Chinese" in the answers. Therefore, learn to combination of lexical chunks in the process of listening, will greatly enhance the student to the conveyed information processing and respond in time, improve the ability of discrimination analysis.

\subsection{Adopt various forms to strengthen language chunks output after Listening training}

After the listening activities, in addition to the interpretation of the relevant content, teachers should consciously strengthen the output of the training of lexical chunks, constantly try to repeat to core of lexical chunks and use, so as to achieve the process of internalization. Can strengthen method are many, such as just heard of language materials, lexical chunks of text classification, and require students to read, perusal; Listen again on the basis of reading language material, lets the student in the process of listening to emphasize the consciousness of lexical chunks. Lexical chunks output training can also through the expansion of lexical chunks replacement, words, sentences, such as teachers can specify the text appears in the phrase of several, asked the students according to the lexical chunks to oral communication, written dialogue, in his writing, etc., can be flexible and varied in form, length of informal, but the content to be coherent, write out the dialogue should be related to a topic. Training students' use of lexical chunks by adopting a variety of forms, students grasp of the language chunks from perception stage can rise to a more flexible and freely use phase.

\section{CONCLUSION}

In listening activities, many factors will affect the improvement of listening comprehension ability. Such as mother tongue thinking, listening skills, etc. To language teaching method is applied in the listening teaching Chinese as a foreign language, consciously cultivate awareness of lexical chunks in the hearing training, more learning, more accumulation, strengthen the learning and memory of lexical chunks, can help students overcome these barriers, improve the information processing of listening material, improve the ability of listening comprehension.

\section{REFERENCES}

[1] Altenberg B. \& Granger S. (2001) "The Grammatical and Lexical Patterning of MAKE in Native and Non-native Student Writing”. Applied Linguistics, 22(2), 173 - 194.

[2] Gong-Yu Jin (2009), Lexical chunks theory and college English listening teaching. The three friends of the science. In November.

[3] wen-long wang (2013). Primary stage of lexical chunks to construct study Chinese as a foreign language. The Peking University. Doctoral thesis in.

[4] Ping-wen Chen (2007). Theory and its use in English teaching of lexical chunks. Journal of Shan Dong normal university school of foreign languages: Basic English education. 